\title{
Current concept review: quality and process improvement in orthopedics
}

This article was published in the following Dove Press journal:

Orthopedic Research and Reviews

23 December 2015

Number of times this article has been viewed

\section{Stephen J Pinney' \\ Alexandra E Page ${ }^{2}$ \\ David S Jevsevar ${ }^{3}$ \\ Kevin J Bozic ${ }^{4}$}

'Department of Orthopaedic Surgery, St Mary's Medical Center, San

Francisco, CA, USA; ${ }^{2}$ Orthopaedic Surgery, AAOS Health Care Systems Committee, San Diego, CA, USA; ${ }^{3}$ Department of Orthopaedics, Geisel School of Medicine, Dartmouth University, Hanover, NH, USA; ${ }^{4}$ Department of Surgery and Perioperative Care, Dell Medical School at the University of Texas, Austin, TX, USA

\section{Video abstract}

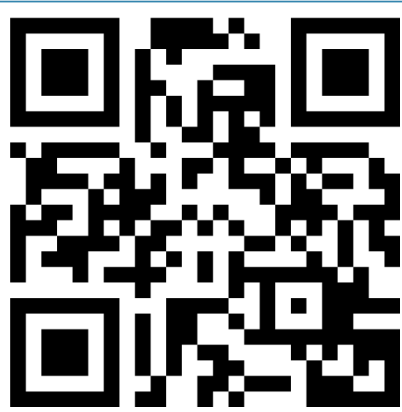

Point your SmartPhone at the code above. If you have a QR code reader the video abstract will appear. Or use: http://youtu.be/2ixal UogtYY4

Correspondence: Stephen J Pinney Department of Orthopaedic Surgery, St Mary's Medical Center, One Shrader St, Suite 650, San Francisco, CA, 94117, USA

Tel +I 4I5 22I 0665

$\mathrm{Fax}+\mathrm{I} 4152210687$

Email sjpinney@yahoo.com
Abstract: Multiple health care stakeholders are increasingly scrutinizing musculoskeletal care to optimize quality and cost efficiency. This has led to greater emphasis on quality and process improvement. There is a robust set of business strategies that are increasingly being applied to health care delivery. These quality and process improvement tools (QPITs) have specific applications to segments of, or the entire episode of, patient care. In the rapidly changing health care world, it will behoove all orthopedic surgeons to have an understanding of the manner in which care delivery processes can be evaluated and improved. Many of the commonly used QPITs, including checklist initiatives, standardized clinical care pathways, lean methodology, six sigma strategies, and total quality management, embrace basic principles of quality improvement. These principles include focusing on outcomes, optimizing communication among health care team members, increasing process standardization, and decreasing process variation. This review summarizes the common QPITs, including how and when they might be employed to improve care delivery.

Keywords: clinical care pathway, musculoskeletal care, outcomes, quality management, six sigma, lean thinking

\section{Introduction}

High-quality patient care should be the primary goal of health care delivery. Multiple health care stakeholders are increasingly scrutinizing musculoskeletal care to optimize quality and cost-efficiency. High value (ie, best quality at lowest price) has been fundamental in the business world, and recent changes in health care payment and delivery have resulted in a paradigm shift which should impact how orthopedic surgeons, and all physicians, view quality.

Legendary orthopedic surgeon Ernest Codman proposed the "end results idea" in 1910:

The common sense notion that every hospital should follow every patient it treats, long enough to determine whether or not the treatment has been successful, and then to inquire,

"If not, why not?" with a view to preventing similar failures in the future. ${ }^{1}$

Based on these ideas, Codman should be considered an early proponent of systematic quality and process improvement, and he is often credited with being the father of evidence-based medicine in orthopedics. ${ }^{2}$ Over 100 hundred years later, emphasis on the overall episode of care (EOC), addressing the full cycle of patient care from start to finish including both the patient's outcome and the associated cost, demands revisiting the idea of quality and process improvement. ${ }^{3}$ The trend to provide bundled submit your manuscript | www.dovepress.com

Dovepress

http://dx.doi.org//0.2147/ORR.S92216 
payments for specific patient EOCs and the incorporation of performance measures may form a foundation for health care payment and delivery in the years ahead. ${ }^{4}$ These models are emphasized in the Patient Protection and Affordable Care Act (PPACA) and implicit in the alternative payment models identified in descriptions for repeal and reform of the Medicare Sustainable Growth Rate (SGR). ${ }^{5}$ They are increasingly common features of many insurance companies' compensation models. ${ }^{6}$ This approach demands that all providers involved in patient care work together toward common goals. In this model, orthopedic surgeons are ideally situated to lead quality improvement initiatives on behalf of their patients. The purpose of this report is to review the orthopedic, health care, and business literature on the topics of quality and process improvement and to identify principles and tools for improving the quality and value of orthopedic care.

Relevant orthopedic and health care publications were identified via a series of PubMed searches that used the search terms "quality" and "quality improvement" and combined them with "orthopaedics", "surgery", and "medicine". A limited number of potentially relevant articles were identified and reviewed, and appropriate references cited in these articles were also identified and reviewed. Information related to the use of quality improvement tools in business came from the American Society of Quality (ASQ) and other relevant business sources. $^{7-10}$

The shift toward high-value, integrated health care accelerated after the Institute of Medicine (IOM)'s 2001 landmark report: Crossing the Quality Chasm: A New Health System for the 21st Century. ${ }^{11}$ This report outlined a series of principles for health care system redesign and helped clarify the definition of health care quality. This report was a follow-up to the IOM's 2000 report, To Err is Human: Building a Safer Health System, which highlighted how uncoordinated care in a fragmented system can have a profoundly negative effect on patient safety. ${ }^{12}$ The importance of the health care system as a whole was furthered in 2001 when the Accreditation Council of Graduate Medical Education (ACGME) added systems-based practice as one of the six core competencies. ${ }^{13}$ The ACGME defined systembased practice as an "awareness of and responsiveness to the larger context and system of health care, as well as the ability to call effectively on other resources in the system to provide optimal health care". ${ }^{14}$ These reports and changes emphasize on evolution away from viewing surgery as an isolated technical event and toward a well-coordinated, integrated team-based approach to surgical care - where patient outcomes are measured and quality and value are a central focus.

\section{Quality and value}

Quality was defined in Crossing the Quality Chasm: A New Health System for the 21st Century, which identified six aims for improving health care and noted that quality health care should be safe, effective, patient-centered, timely, efficient, and equitable (Table 1). ${ }^{11}$ Value-based medicine refers to providing care based on the value conferred by a health care intervention or EOC. ${ }^{15}$ Value in this definition refers to health outcomes achieved per dollar spent. ${ }^{7}$ Evaluating value and cost-effectiveness should first provide a patient the intervention offering the best possible outcome for treating the disease or injury. Only when the outcome conferred by alternative interventions is similar does cost-effectiveness become an issue. Increasingly, evidence suggests that high-value health care does not equate to expensive medical care. ${ }^{16,17}$ However, achieving high-value care requires incorporating quality and process improvement strategies and tools.

Quality and process improvement tools (QPITs) have been developed in other industries to improve the quality, value, and/or efficiency of multistep processes. With increased scrutiny on patient outcomes and trends to optimize health care value by all payers, quality improvement practices have become increasingly accepted and are now emerging as standard practice in health care. Depending on the specific needs of various stakeholders within an integrated health care model, the goals of different quality improvement practices will vary. Several key principles emphasized by various QPITs are summarized in Table 2. Akin to choosing the most appropriate surgical instrument for a particular step in

Table I Six dimensions of a quality health care system

\section{A quality health care system should be}

I. Safe: patients are not harmed by care intended to help them.

2. Effective: services are provided to those who could benefit, based on scientific knowledge, and not provided to those not likely to benefit (ie, avoid underuse and overuse).

3. Patient-centered: the care provided is respectful of patient preferences, needs, and values, and clinical decisions are guided by patient values.

4. Timely: wait times and delays that may be harmful are reduced for those who receive care and those who give care.

5. Efficient: waste of equipment, supplies, ideas, and energy is avoided.

6. Equitable: quality of care is consistent across patient characteristics such as sex, ethnicity, geographic location, and socioeconomic status.

Notes: Data from: Committee on Quality of Health Care in America, Institute of Medicine. Crossing the Quality Chasm: A New Health System for the 2Ist Century. Washington: National Academies Press; 200I." 
Table 2 Principles that may be emphasized by various quality and process improvement tools

\begin{tabular}{|c|c|}
\hline Principle & Example of potential strategy \\
\hline I. Reduce the rate of errors and adverse events. & $\begin{array}{l}\text { Identify "at-risk points" for errors at specific steps within the } \\
\text { system. }\end{array}$ \\
\hline 2. Eliminate waste associated with the process. & $\begin{array}{l}\text { Search for and remove steps or inputs that do not improve the } \\
\text { quality, value, or efficiency of the episode of care. }\end{array}$ \\
\hline 3. Improve the flow and resulting efficiency of a multistep process. & $\begin{array}{l}\text { Identify and eliminate process bottlenecks or unnecessary } \\
\text { delays. }\end{array}$ \\
\hline 4. Minimize the variances within the process. & $\begin{array}{l}\text { Decrease variations that may arise from differing health care } \\
\text { providers, times of treatment, and patient demographics. }\end{array}$ \\
\hline 5. Improve communication among members of the health care team. & $\begin{array}{l}\text { Introduce specific strategies to decrease communications } \\
\text { breakdowns and improve communication and coordination of } \\
\text { care between members of the health care team. }\end{array}$ \\
\hline 6. Improve systematization of the process. & $\begin{array}{l}\text { Increase the likelihood that two patients with a similar condition } \\
\text { would have similar experiences. }\end{array}$ \\
\hline 7. Enhance the patient's experience of care. & $\begin{array}{l}\text { Improve the likelihood that the patient would report their } \\
\text { health care experience as positive. }\end{array}$ \\
\hline
\end{tabular}

a surgical procedure, different QPITs may be required when looking to improve different parts of the EOC.

This review of the current concepts describes the most common QPITs, each of which utilizes one or more of the principles listed in Table 2, and then explores the framework for using QPITs in orthopedics.

\section{Tools for quality and process improvement throughout the EOC}

A review of the literature identified 14 commonly used QPITs (Table 3). The first five tools described here (ie, checklist initiatives, clinical practice guidelines [CPGs], appropriate use criteria [AUCs], clinical care pathways, and standardized clinical assessment and management plans [SCAMPs]) are relatively static, albeit powerful, tools to help standardize and thereby improve care. In recent years, other QPITs such as lean thinking, six sigma, and total quality management (TQM) have emerged from the manufacturing and business sectors to actively foster a redesign of health care and/or provide a means of ongoing process improvement. These encompass the remainder of the QPITs reviewed in this section.

\section{Checklist initiatives}

Checklists are an increasingly common QPIT designed to systematize a specific aspect of the larger EOC. In the example of a hip fracture EOC, a checklist might be utilized to help standardize a specific event, such as transferring the patient from the ER to the ward, performing a team-oriented timeout prior to commencing surgery, or discharging the patient from the hospital. Checklists are updated on a periodic basis and emphasize standardization of specific steps and communication rather than process redesign.
The development and popularization of formalized checklists as a means of systematizing health care events has resulted in dramatic reduction in complications, death, and expenses. ${ }^{18}$ The World Health Organization (WHO)'s Safe Surgery Saves Lives program uses a surgical safety checklist as a critical component of a safe surgical procedure. ${ }^{19}$ Effectively used checklists can achieve goals, including standardizing processes, proactively identifying issues which may negatively impact care, and improving team member communication. However, checklist effectiveness may be limited by factors, including failure to utilize the checklist as intended, an incomplete checklist, or failure to utilize checklists as interactive communication tools.

The Safe Surgery Saves Lives Study Group published the results of a multicenter cohort study examining the inhospital complication rate pre- and post-introduction of a formalized surgical checklist program. ${ }^{20}$ The study prospectively established a baseline in-hospital complication rate across eight hospitals representing geographic and economic diversity. A formal surgical safety checklist was introduced, consisting of 19 items divided into three phases: a sign-in prior to induction of anesthesia, a time-out immediately prior to incision, and a sign-out prior to the patient leaving the operating room. Postintervention data reported a decline in death rate from $1.5 \%$ to $0.8 \%(P=0.003)$ and inpatient complications from $11.0 \%$ to $7.0 \%(P<0.001)$.

\section{CPGs}

CPGs are specific guidelines to aid diagnosis and management that are created by analyzing the existing scientific literature using the principles of evidence-based medicine. For example, in the case of a hip fracture patient, CPGs can guide 
Table 3 Summary of QPITs

\begin{tabular}{|c|c|c|c|c|}
\hline QPIT & Description & $\begin{array}{l}\text { Application } \\
\text { (event vs } \\
\text { entire EOC) }\end{array}$ & $\begin{array}{l}\text { Static vs } \\
\text { iterative }\end{array}$ & $\begin{array}{l}\text { Standardize } \\
\text { vs redesign }\end{array}$ \\
\hline Checklist initiatives & $\begin{array}{l}\text { Standardizes and improves team communication around } \\
\text { a specific event by formally reviewing a preset checklist. }\end{array}$ & $\begin{array}{l}\text { Specific event (eg, } \\
\text { surgical timeout) }\end{array}$ & Static & Standardize \\
\hline CPGs & $\begin{array}{l}\text { Formal guidelines for diagnosis or management of } \\
\text { a clinical situation that are usually generated in an } \\
\text { evidence-based manner. }\end{array}$ & Specific event & Static & Standardize \\
\hline AUCs & $\begin{array}{l}\text { Guidelines developed based on the collective judgment } \\
\text { of experts on the appropriateness of various diagnostic } \\
\text { testing and treatment options in specific clinical scenarios. }\end{array}$ & Specific event & Static & Standardize \\
\hline $\begin{array}{l}\text { Care pathways (clinical } \\
\text { pathways, care map) }\end{array}$ & $\begin{array}{l}\text { A formal pathway that outlines how care for a specific } \\
\text { condition is to be delivered throughout the entire EOC. }\end{array}$ & Entire EOC & Static & Standardize (once in place) \\
\hline SCAMP & $\begin{array}{l}\text { A care path developed with increased emphasis on the } \\
\text { use of evidence-based literature and employing real-time } \\
\text { feedback and data analysis, allowing for regular changes } \\
\text { to the pathway as needed. }\end{array}$ & Entire EOC & Iterative & Standardize \\
\hline PDCA cycles & $\begin{array}{l}\text { A four-step, iterative, continuous improvement cycle } \\
\text { that envisions what the process should look like ("plan"); } \\
\text { implements the plan ("do"); records the results ("check"); } \\
\text { and adjusts the process based on the results ("act"). }\end{array}$ & $\begin{array}{l}\text { Entire EOC or } \\
\text { a specific event }\end{array}$ & Iterative & Redesign and standardize \\
\hline SQC & $\begin{array}{l}\text { The use of outcome or output data collected as part of } \\
\text { the production process to continuously improve the } \\
\text { process and provide early detection of problems. }\end{array}$ & $\begin{array}{l}\text { Entire EOC or } \\
\text { a specific event }\end{array}$ & Iterative & Standardize \\
\hline $\begin{array}{l}\text { Lean process } \\
\text { improvement }\end{array}$ & $\begin{array}{l}\text { A multidisciplinary, team-based process for improving value } \\
\text { and flow in the provision of services that was developed by } \\
\text { the Toyota motor company. }\end{array}$ & $\begin{array}{l}\text { Entire EOC or } \\
\text { a specific event }\end{array}$ & Iterative & Redesign and standardize \\
\hline Six sigma & $\begin{array}{l}\text { A process improvement strategy introduced by the } \\
\text { Motorola company that focuses on I) decreasing the rate } \\
\text { that defects (errors) occur, and 2) reducing variation in } \\
\text { the production process. }\end{array}$ & Entire EOC & Iterative & Redesign and standardize \\
\hline Lean six sigma & $\begin{array}{l}\text { An amalgamation of the principles of lean (eliminating } \\
\text { waste and improving workflow) and six sigma (decreasing } \\
\text { the rate of errors and reducing process variation). }\end{array}$ & $\begin{array}{l}\text { Entire EOC or a } \\
\text { specific event }\end{array}$ & Iterative & Redesign and standardize \\
\hline TQM & $\begin{array}{l}\text { A comprehensive approach to continuous quality } \\
\text { improvement of the entire process involving all members } \\
\text { of the health care team including patients. }\end{array}$ & Entire EOC & Iterative & Redesign and standardize \\
\hline PFCC methodology & $\begin{array}{l}\text { A six-step, continuous improvement process developed } \\
\text { specifically for health care based on TQM principles. }\end{array}$ & Entire EOC & Iterative & Redesign and standardize \\
\hline $\mathrm{RCA}$ & $\begin{array}{l}\text { A formalized approach to evaluating the cause or causes } \\
\text { of an adverse event. }\end{array}$ & Specific event & Static & Redesign and standardize \\
\hline FMEA & $\begin{array}{l}\text { A proactive approach to preventing adverse events by } \\
\text { identifying potential failure modes within the } \\
\text { existing system. }\end{array}$ & Specific event & Static & Redesign and standardize \\
\hline
\end{tabular}

Abbreviations: AUCs, appropriate use criteria; CPGs, clinical practice guidelines; EOC, episode of care; FMEA, failure modes and effect analysis; PDCA, plan-do-check-act; PFCC, patient- and family-centered care; QPIT, quality and process improvement tool; RCA, root cause analysis; SCAMP, standardized clinical assessment and management plan; SQC, statistical quality control; TQM, total quality management.

clinical decision making at specific points in the EOC, such as what type of preoperative assessment is required, which type of operation is indicated, and what postoperative pain regimen should be employed. ${ }^{21,22}$ The goal of a CPG is to standardize treatment of a specific condition using best practices and thus reduce poor outcomes. Although CPGs can be generated by consensus or even arbitrarily, the accepted standard for CPG development is that they be evidence-based. ${ }^{23}$ The American
Academy of Orthopaedic Surgeons, through their EvidenceBased Quality and Value Committee, has developed 17 CPGs since 2006. ${ }^{24}$ These workgroups employ a detailed review process of the relevant literature and a multistep peer-review process to create guidelines that reflect the current best available evidence.

There are, however, practical limitations to the use of CPGs. They are time-consuming and expensive to create, and 
effective implementation can be difficult. Furthermore, they are intended to cover specific conditions, but applicability to particular clinical scenarios may be challenging. One notable limitation to evidence-based CPGs is that they are only as good as the quality and relevance of the published research. Unfortunately, because of a lack of clinical equipoise, there are relatively few orthopedic conditions that have multiple high-quality level 1 and 2 studies that allow for strong or even moderate-strength CPGs.

\section{AUCs}

Whereas CPGs tell us whether a procedure or test is acceptable, AUCs tell us when, and for whom, the procedure is appropriate. Similar to CPGs, AUCs are based on a robust review of relevant peer-reviewed literature. They are based, in part, on the concept of the collective judgment of experts. AUCs are currently being developed by the American Academy of Orthopaedic Surgeons using the RAND/UCLA Appropriateness Method. ${ }^{8}$ The underlying goal of this approach is to identify the appropriateness of medical and surgical interventions and diagnostic testing. Appropriateness has been defined as:

the expected health benefit (eg, increased life expectancy, relief of pain, reduced anxiety, improved functional capacity) exceeds the expected negative consequences (eg, mortality, morbidity, anxiety, pain, time lost from work) by a sufficiently wide margin that the procedure is worth doing, exclusive of cost. ${ }^{25}$

However, AUCs differ from CPGs in that, while evidencebased, practicing physicians with different training and clinical expertise independently rate the appropriateness of a wide variety of clinical scenarios for each condition. This allows a large number of treatment scenarios to be rated as either "appropriate", "may be appropriate", or "rarely appropriate". For this reason, AUCs may be more broadly applicable than CPGs.

Presently, the use of both CPGs and AUCs is entirely voluntary. Their existence does not ensure utilization or compliance. However, payers seeking high-value care may increase pressure to adopt evidence-based CPGs. CPGs can help minimize or eliminate the use of poor or ineffective treatments and standardize specific aspects of the EOC, but like checklists, they tend to be "stand alone" tools that apply only to very specific decision points within the EOC. Furthermore, the procedural rigidity in the CPG and AUC creation processes requires significant effort and time to update, which limits rapid incorporation of new information.

\section{Clinical care pathways}

Clinical care pathways outline the care throughout the entire EOC for patients with a specific condition. They have been developed for hip fractures, total knee arthroplasty, and other orthopedic conditions. ${ }^{26-28}$ For example, in the hip fracture EOC scenario, a care pathway would delineate the steps in the preoperative assessment pathway, the operative approach, and the postoperative management plan. It would provide a means of improving the standardization of care and early identification of patients whose clinical situation was falling outside of the normal pathway. Care pathways are intended to reduce treatment variation, improve communication and coordination of care among providers, and ultimately increase the quality and value of care delivered to each patient. Often created via an interdisciplinary team, a care pathway identifies key events in the treatment course (eg, preoperative assessment, postoperative medication, physical therapy routine, etc). Decisions are standardized after a review of the available literature and team discussion. Ideally, care outcomes would be assessed, facilitating care pathway improvements based on the results or as new literature becomes available. Care pathways do not lock providers into rigid treatment regimens. They allow for appropriate unique patient treatment variation, although clear documentation of rationale for deviation is important.

\section{SCAMPs}

SCAMPs are more formalized clinical care pathways. ${ }^{29-31}$ They are developed with an increased emphasis on the evidence-based literature and careful attention to data collection on the outcome of care. SCAMPs also focus on analysis of deviation from the care pathway. This allows for a more iterative approach that facilitates rapid modification as new information and patterns of practice become apparent. As an example, a group of orthopedic surgeons treating hip fractures could elect to develop a SCAMP in the form of a detailed treatment algorithm based on the available literature. This care pathway would be consensus-based and would be tied to the hospital's electronic medical record to allow for continuous data collection. At any point in the care pathway, the treating physician could elect to deviate from the pathway - provided they recorded their reasons for deviating. For example, if the consensus pathway recommended surgical stabilization of the hip fracture within 24 hours of injury, the treating surgeon could delay surgery beyond 24 hours simply by recording his/her rationale for delaying surgery. The variances from the pathway would be recorded and compiled. These targeted data are captured from the electronic medical 
record and then combined with any new literature to allow the orthopedic surgeons overseeing the SCAMP to update it regularly in an iterative manner. Using SCAMPs promotes decreased variation in care while maintaining each physician's autonomy to make the decisions that he/she feels is best for each individual patient.

\section{Plan-do-check-act cycles}

Plan-do-check-act (PDCA) is a four-step, iterative, continuous improvement cycle that was embraced by Japanese manufacturers following the Second World War. Treating hip fractures in the hospital setting, a group could use the PDCA cycle by first looking at the entire EOC for a hip fracture patient and planning what they think should happen at each step. This plan would then be implemented (the "do"), checked to see how it was working (the "check"), and then continually adjusted based on how the process was going (the "act" or "adjust"). PDCA can be applied to an entire process or a subsection of the process. Used in a cyclic manner, PDCA allows refining and stabilization of a process over time.

"Plan" is the first step, establishing clear outcome goals for the process and envisioning the means to achieve the goals. This could include modifications to an existing process or outlining an entirely new process. A period of observation often precedes outlining the plan to improve understanding of existing processes. The second step, “do", implements the plan and collects data on the results. The third step, "check", reviews the results of the process to determine what worked and what needs improvement. Careful analysis based on obtaining accurate outcome data during the "do" phase is required. The final step is to "act" or adjust - identifying changes or corrections needed to obtain the desired results. One defining feature of a PDCA approach to process improvement is that individual workers at every level of the organization have the ability and responsibility of stopping or correcting the production process if they detect a problem. This approach emphasizes the integral nature of workers to process improvement.

Torkki et $\mathrm{al}^{32}$ used a PDCA approach to decrease the turnover time and improve the overall efficiency in managing urgent surgical cases. Implemented changes included induction of anesthesia outside of the operating rooms, which resulted in a $20.5 \%(P<0.05)$ decrease in wait times and a $9.7 \%(P<0.001)$ increase in efficiency.

\section{Statistical quality control}

The first iteration of statistical quality control (SQC) was developed in the 1920s. SQC and early versions of the PDCA cycle are the basis for many QPITs that followed. SQC relies on statistical methods and is designed for production processes with uniform outcomes that can be measured. It uses outcome or output data collected to continuously improve the process and provide early detection of problems. For example, the physical functioning of a hip fracture patient could be formally assessed daily following surgery. Patients unable to reach a certain functional level by the third postoperative day would be identified, and more intensive intervention would be provided.

A core feature of SQC is the control chart that identifies abnormal variation within a process. The SQC first requires understanding the process as a whole with a process map. The second element is to utilize control charts to assess variation in both individual parts as well as the process as a whole. The third step requires eliminating nonrandom variations and random variations that are not within the normal acceptable range. Finally, the production process is monitored statistically to allow early detection of unacceptable errors or waste. This serves to eliminate or minimize the need for postproduction inspection.

Seim et $\mathrm{al}^{33}$ studied the use of statistical process control (SPC) as applied to measuring nonoperative time during the perioperative period. SPC is a subset of SQC that looks specifically at the quantifiable outputs of a process. After developing a clinical pathway designed to decrease operating room turnover time, they implemented a real-time process for measuring the time between surgical cases. This data collection allowed identification of a decrease in operating room turnover time within 2 days of the implementation of the redesigned clinical pathway. Furthermore, by establishing this type of SPC with ongoing data collection, they were able to identify any changes in operating room turnover time performance over time.

\section{Lean process improvement}

Originally developed by Toyota to improve value for their customers, ${ }^{9}$ the term "lean" describes a multidisciplinary, team-based process for improving value and flow in the production of goods or services. The central goal of lean process improvements is to eliminate waste - any action or process that does not enhance the value of the product or service. Later, emphasis on flow was added, improving the process by decreasing variances. Lean process improvement represents a series of tools such as value stream mapping to evaluate and address the process. It is ideally applied to the entire process. However, it may be more practically applied to a segment of the overall process. For example, a lean 
intervention could be undertaken with the goal of decreasing the average time from admission to surgery in patients with hip fractures.

Collar et a ${ }^{34}$ utilized lean methodology to decrease operating room turnover time for otolaryngology surgery. A lean intervention that consisted of assembling a multidisciplinary team and an initial value stream mapping of the steps required to turnover an operating room was implemented. These steps were analyzed using a "swim lane" diagram, whereby each employee and role was identified and compared to the critical steps of the workflow. The group identified work that seemed to add no value. Waste can be broken down into categories such as motion, transport, inventory, waiting, overprocessing, or overproduction. After establishing the root cause, an attempt was made to eliminate the waste. For example, there was often a delay in preparing instrumentation between cases due to the failure of the cleaning technician to prepare the room immediately after it was vacated. To address this, the cleaning technician was automatically paged when dressings were being applied. This and other interventions were implemented, reducing operating room turnover time from 38 to 29 minutes $(P<0.001)$ during the implementation period compared to the baseline period.

\section{Six sigma}

Originally introduced by Motorola in 1985, six sigma is a process improvement strategy comprising various tools and strategies. It focuses on 1) improving the quality of a process by decreasing the "defects" (errors) rate, and 2) reducing variability in the production process. The designation of "six sigma" refers to the goal of achieving a mature production process with an error rate of less than 3.4 errors per million, or six standard deviations from the process mean. This error rate is largely symbolic and the designation of a six sigma process improvement project is determined by the project ideals rather than the final error rate. These ideals include a continuous effort to reduce process variation, a commitment to measure and analyze results, and widespread organizational adoption of this philosophy beginning in upper management. Successful incorporation of six sigma process improvement requires a series of "champions" within each organization. A medical "champion" to lead the project has been identified as an essential component for the success of coordinator-based orthopedic programs for the secondary prevention of fragility fractures. ${ }^{35}$ Champions are often credentialed similar to a martial arts program with designations of orange belts, green belts, and black belts, depending on their experience and demonstrated knowledge of the six sigma process. Tools that are used in the six sigma process include analysis of variance, cause and effect diagrams, and cost-benefit analysis. However, the underlying methodology for a six sigma project follows a standardized format. Projects seeking to improve an existing process use a DMAIC (define, measure, analyze, improve, control) approach, whereas projects creating a new product or service use a DMADV (define, measure, analyze, design, verify) approach. Both of these methodologies were based, in part, on the PDCA cycle.

\section{Lean six sigma}

As the name suggests, this process improvement approach amalgamates the lean and six sigma tools. ${ }^{36}$ Lean focuses on eliminating waste and improving workflow, whereas six sigma decreases the rate of errors (defects) and reduces process variation, making the tools complementary. Quality improvement using lean six sigma also employs the DMAIC framework. However, core elements of lean methodology such as value stream mapping are also incorporated into the framework, creating a reproducible synergistic approach.

A comprehensive lean six sigma intervention applied to hip fracture care demonstrated a decrease in hospital length of stay of 4.2 days $(-31 \%)$ and average duration of surgery of 57 minutes $(-36 \%) \cdot{ }^{37}$ The authors identified a series of variables that predicted a prolonged length of stay in their hip fracture population. After an analysis of the factors affecting length of stay, potential interventions were trialed. Ultimately, the coordinated and iterative nature of the lean six sigma framework served to identify and then sustain various changes in care delivery that led to the striking improvements in the target outcome metrics.

\section{TQM}

TQM focuses on continuous improvement of the product or process using an integrative approach that looks at the entire production process and involves all members of the production team, including customers. This customer-based approach espouses the idea that everyone involved in the production process should be accountable for the end result. TQM is characterized by a series of elements, including:

- Customer-centered: customers will ultimately determine how effective the product or process has been.

- Complete employee involvement: all employees work toward a common goal, empowered to think and work toward best outcomes with strategies such as self-managed work teams. 
- Process-centered: TQM focuses on understanding the entire process and looking for ways that the process may be improved.

- Integration: complex processes with many steps (eg, preoperative assessment, anesthesia, ward nursing, postoperative physical therapy, etc) optimally should be horizontally integrated.

- Strategic management: management must fully commit to the tenets of TQM, including employee involvement, process analysis, and the quality of the product.

- Continual process improvement.

- Fact-based decision making: collection of accurate data as an integrated part of the production process is essential to facilitate fact-based decisions.

- Communication: clear and horizontal communication between management and employees throughout the production process is essential. ${ }^{10}$

TQM applied to health care is a formal extension of patient-centered care: seeing the care experience from the patient's perspective and altering the design of care delivery to ensure that the patient's experience is optimized. An important aspect of TQM and other QPITs is accurate, patientcentered outcome metrics. ${ }^{38}$ Traditionally, orthopedic and other health care outcome metrics have not been particularly patient-centered, often relying more on physician reporting and objective measures rather than the patient's subjective experience. However, as illustrated by the creation of the Patient-Centered Outcomes Research Institute (PCORI), there is a movement to develop new outcome metrics that highlight the critical importance of the patient's viewpoint in assessing the effectiveness of care delivery. ${ }^{39}$

\section{Patient- and family-centered care methodology}

Patient- and family-centered care (PFCC) methodology is a QPIT based on design science and experience-based design that applies the TQM concepts to health care. ${ }^{40}$ Specifically, it focuses on viewing the entire care delivery process through the eyes of the patient and their family. It is a six-step continuous improvement process applied to the EOC to improve outcomes and value. ${ }^{41}$ Step 1 selects a care experience needing improvement (eg, total hip replacement). Step 2 establishes a PFCC guiding council to oversee the process. Step 3 involves assessing the current state through the eyes of the patients and their families - often by a series of shadowing exercises. Step 4 develops a PFCC working group based on touchpoints - any point where a caregiver comes in contact with a patient or their family members. Step 5 focuses on creating a shared vision of the ideal patient and family care experience to serve as a goal. Finally, step 6 identifies PFCC improvement projects that may use other QPITs to continuously refine the process and improve the quality and value of patient care.

DiGioia and Greenhouse applied the six-step PFCC methodology to a large total joint replacement program. ${ }^{42}$ They described the iterative progression of the PFCC program over a 4-year period. Results included a patient satisfaction rate at the 99th percentile nationally. They lowered their postoperative infection rates for hip and knee joint replacements to $0.7 \%$ and $0.3 \%$, respectively, compared to the national averages of $1.7 \%$ and $2.4 \%$, respectively. They decreased their average length of stay to 2.6 and 3.0 days compared to national averages of 4.9 and 3.8 days for hip and knee replacements, respectively. In addition, they reported a decrease in staff turnover by $66 \%$. They concluded that the PFCC provided an easy-to-use framework to "simultaneously improve financial and clinical outcomes by redefining value as what is important to patients and families." ${ }^{\text {"42 }}$

\section{Root cause analysis}

Root cause analysis (RCA) is a formalized approach to evaluating the underlying cause or causes of an adverse event. The Joint Commission: Accreditation, Health Care, Certification mandates that hospitals perform an RCA following any sentinel event. ${ }^{43}$ Medical failures or near misses have long been seen as opportunities to learn - often in the form of morbidity and mortality rounds. ${ }^{44}$ However, unlike traditional morbidity and mortality rounds, an RCA is an in-depth systematic analysis of all of the factors leading to the adverse event. ${ }^{45}$ The National Patient Safety Foundation (NPSF) recommends that, in addition to a detailed analysis of the adverse event, RCAs must focus on implementing actionable recommendations that aim to prevent a recurrence of the sentinel event. ${ }^{46}$ The NPSF also highlights the importance of having high-level administrative leadership involved in and supportive of the RCA process. They specified that an RCA should be commenced within 72 hours of recognizing that a review is needed, and they recommend that RCA teams should comprise four to six individuals from all levels of the organization, including a process expert. However, team membership should not involve individuals who were involved in the event under review, although these individuals should be interviewed. RCA should be viewed as a learning experience that reviews all the elements that contributed to the failure, emphasizing the role of the system as a whole. One report of an RCA 
identified that inadequate communication between a medical consultant and an anesthesiologist contributed to the death of a 78-year-old woman with a hip fracture. The RCA of this event and resulting recommendations led to institutional changes that subsequently decreased the in-hospital mortality rate from $4.9 \%$ to $1 \%{ }^{47}$

\section{Failure modes and effect analysis}

RCAs are retrospective reviews and have the limitation of occurring after a major problem has happened. In contrast, failure modes and effect analysis (FMEA) has been proposed as a means to prevent failures. ${ }^{48} \mathrm{FMEA}$ is a type of prospective hazard analysis tool that was developed by the US military and the National Aeronautics and Space Administration (NASA) to identify potential failure modes and proactively take steps to minimize the risk of these errors occurring. This form of proactive risk management has been promoted by the Joint Commission: Accreditation, Health Care, Certification. ${ }^{43}$ The FMEA process in health care usually involves a multidisciplinary group. Potential failures in a specific aspect of care delivery (eg, postoperative infection) are identified systematically. For each potential failure mode, the probability of the failure, the severity of the failure, and how it would be detected are identified. A process redesign is then instituted for potential failure modes that are identified and for which there are no or minimal safety precautions built into the care delivery system.

FMEA has been used to improve the safety of intravenous (IV) drug administration. ${ }^{49}$ A multidisciplinary medication safety team performed a proactive analysis and identified a series of potential IV medication errors (ie, failures). These included misinterpretation of the order, administering the wrong medication or wrong dosage, using the wrong diluent, or entering the incorrect information into the IV infusion pump. The analysis subsequently determined that entering incorrect information in the infusion pump represented the highest critical index. To help address this, pumps with additional safety features were instituted. Subsequently, the rate of pump-related errors dropped from $41 \%$ to $22 \%$ in the ensuing 12 months.

\section{Framework for using QPITs}

In thinking about QPITs, it may be helpful to view them through a framework that delineates whether they:

- are applied to the entire EOC or a specific segment of the EOC;

- iteratively adjust the process versus work statically; and

- focus more on standardizing an existing process (eg, to decrease variations and errors) versus redesigning a process (eg, to decrease waste).
QPITs may focus on a specific event within the EOC (eg, checklist initiatives, AUCs, and CPGs) or the entire EOC (eg, clinical care pathways, patient- and family-centered care model). Many QPITs can be used in either a focused or broad manner. For example, both the PDCA cycle and lean thinking can be applied to a specific event (eg, operating room turnover time) or to the entire EOC.

QPITs can also be differentiated based on the extent to which they are iterative. All QPITs are intended to modify the process over time based on the results obtained. However, tools such as lean thinking and PDCA cycles are designed to adjust the process in real time based on the results that are achieved. These types of iterative QPITs allow for continuous quality improvement of the process. In contrast, tools such as checklist initiatives and CPGs are more static, although to remain effective they must be updated periodically.

QPITs may focus on standardizing an existing process to improve quality and value or emphasize process redesign. Standardizing an existing process is often achieved via minimizing process variation, whereas process redesign is performed by identifying more effective means to achieve the overall goal.

Successful implementation of QPITs requires total engagement by all members of the patient care team, including not only the orthopedic surgeons, but also the nurses, physiotherapists, medical assistants, and administrators. All staff must be committed to the improvement process, regardless of whether the QPIT is applied to all or only part of the EOC, is iterative or static, involves standardization of an existing process, or involves process redesign.

\section{Conclusion}

The increasing emphasis on quality, efficiency, and value in health care will result in far-reaching changes in how health care is delivered and financed in the coming decades. Many of these changes emphasize optimization of the quality and efficiency over the entire EOC rather than isolated elements of patient care. Surgeons typically oversee their patient's entire EOC and therefore will be well positioned to assume leadership roles within this new health care paradigm. To do so effectively, they will need to embrace the team-based quality improvement movement. The QPITs that have been outlined in this review can provide the means to improve quality, efficiency, and value.

\section{Acknowledgment}

The authors thank Dagmar Gross for assistance with preparation of this manuscript, which was supported by 
the authors. No financial or material support was received for this paper.

\section{Disclosure}

The authors report no conflicts of interest in this work.

\section{References}

1. Donabedian A. The end results of health care: Ernest Codman's contribution to quality assessment and beyond. Milbank Q. 1989;67(2):233-256.

2. Brand RA. Ernest Amory Codman, MD, 1869-1940. Clin Orthop Relat Res. 2009;467:2763-2765.

3. Porter ME. What is value in health care? N Engl J Med. 2010;363(26): 2477-2481.

4. Enquist M, Bosco JA 3rd, Pazand L, Habibi KA, Donoghue RJ, Zuckerman JD. Managing episodes of care: strategies for orthopaedic surgeons in the era of reform. J Bone Joint Surg Am. 2011;93(10):e55.

5. The Patient Protection and Affordable Care Act. Public Law 111-148, 124 Stat 119. March 23, 2010. Available from: www.gpo.gov/fdsys/pkg/ PLAW-111 publ148/pdf/PLAW-111publ148.pdf. Accessed October 28, 2015.

6. Guterman S, Zezza MA, Schoen C. Paying for value: replacing Medicare's sustainable growth rate formula with incentives to improve care. The Commonwealth Fund. 2013;1678(16):1-10.

7. Porter ME, Teisberg EO. Redefining Health Care: Creating ValueBased Competition on Results. Boston: Harvard Business School Press; 2006.

8. Fitch K, Bernstein SJ, Aguilar MD, et al. The RAND/UCLA Appropriateness Method User's Manual. Santa Monica: RAND Corporation; 2001.

9. Krafcik JF. Triumph of the lean production system. Sloan Manage Rev. 1988;30(1):41-52.

10. Westcott RT, editor. Chapter 12: Quality Models and Theories. The Certified Manager of Quality/Organizational Excellence Handbook. 3rd ed. Milwaukee: ASQ Quality Press; 2005: 304-305.

11. Committee on Quality of Health Care in America, Institute of Medicine. Crossing the Quality Chasm: A New Health System for the 21st Century. Washington: National Academies Press; 2001.

12. Kohn LT, Corrigan JM, Donaldson MS, editors; Committee on Quality of Health Care in America, Institute of Medicine. To Err is Human: Building a Safer Health System. Washington: National Academies Press; 2000.

13. Roberts SM, Jarvis-Selinger S, Pratt DD, et al. Reshaping orthopaedic resident education in systems-based practice. J Bone Joint Surg Am. 2012;94:e1131-e1137.

14. Accreditation Council for Graduate Medical Education Competency: Systems-Based Practice. Available from: http://www.ecfmg.org/echo/ acgme-core-competencies.html. Accessed July 31, 2014.

15. Brown MM, Brown GC. Update on value-based medicine. Curr Opin Ophthalmol. 2013;24(3):183-189.

16. Berwick DM, Nolan TW, Whittington J. The triple aim: care, health, and cost. Health Aff (Millwood). 2008;27(3):759-769.

17. Fonarow GC, Stevenson LW, Walden JA, et al. Impact of a comprehensive heart failure management program on hospital readmission and functional status of patients with advanced heart failure. J Am Coll Cardiol. 1997;30(3):725-732.

18. Pronovost $\mathrm{P}$, Needham D, Berenholtz S, et al. An intervention to decrease catheter-related bloodstream infections in the ICU. $N$ Engl $J$ Med. 2006;355:2725-2732.

19. World Health Organization. Safe Surgery Saves Lives. Available from: http://www.who.int/patientsafety/safesurgery/tools_resources/ 9789241598552/en/. Accessed October 29, 2015.

20. Haynes AB, Weiser TG, Berry WR, et al; Safe Surgery Saves Lives Study Group. A surgical safety checklist to reduce morbidity and mortality in a global population. $N$ Engl J Med. 2009;360(5):491-499.
21. Mak JC, Cameron ID, March LM; National Health and Medical Research Council. Evidence-based guidelines for the management of hip fractures in older persons: an update. Med J Aust. 2010;192(1):37-41.

22. Roberts KC, Brox WT, Jevsevar DS, Sevarino K. Management of hip fractures in the elderly. J Am Acad Orthop Surg. 2015;23(2):131-137.

23. Graham R, Mancher M, Wolman DM, Greenfield S, Steinberg E, editors; Committee on Standards for Developing Trustworthy Clinical Practice Guidelines; Board on Health Care Services; Institute of Medicine. Clinical Practice Guidelines We Can Trust. Washington: National Academies Press; 2011.

24. American Academy of Orthopaedic Surgeons [website on the Internet]. Evidence-based clinical practice guidelines. Available from http://www. aaos.org/research/guidelines/guide.asp. Accessed October 28, 2015.

25. Brook RH, Chassin MR, Fink A, Solomon DH, Kosecoff J, Park RE. A method for the detailed assessment of the appropriateness of medical technologies. Int J Technol Assess Health Care. 1986;2(1):53-63.

26. Kumar G. Protocol-guided hip fracture management reduces length of hospital stay. Br J Hosp Med (Lond). 2012;73(11):645-648.

27. Macario A, Horne M, Goodman S, et al. The effect of a perioperative clinical pathway for knee replacement surgery on hospital costs. Anesth Analg. 1998;86(5):978-984.

28. Kim S, Losina E, Solomon DH, Wright J, Katz JN. Effectiveness of clinical pathways for total knee and total hip arthroplasty: literature review. J Arthroplasty. 2003;18(1):69-74.

29. Farias M, Jenkins K, Lock J, et al. Standardized clinical assessment and management plans (SCAMPs) provide a better alternative to clinical practice guidelines. Health Aff (Millwood). 2013;32(5):911-920.

30. Farias M, Friedman KG, Lock JE, Rathod RH. Gathering and learning from relevant clinical data: a new framework. Acad Med. 2015; 90(2):143-148.

31. Rathod RH. SCAMPs: a new tool for an old problem. J Hosp Med. 2015;10(9):633-636.

32. Torkki PM, Alho AI, Peltokorpi AV, Torkki MI, Kallio PE. Managing urgent surgery as a process: case study of a trauma center. Int J Technol Assess Health Care. 2006;22(2):255-260.

33. Seim A, Andersen B, Sandberg WS. Statistical process control as a tool for monitoring nonoperative time. Anesthesiology. 2006;105(2): 370-380.

34. Collar RM, Shuman AG, Feiner S, et al. Lean management in academic surgery. J Am Coll Surg. 2012;214(6):928-936.

35. Marsh D, Akesson K, Beaton DE, et al; IOF CSA Fracture Working Group. Coordinator-based systems for secondary prevention in fragility fracture patients. Osteoporos Int. 2011;22(7):2051-2065.

36. de Koning H, Verver JP, van den Heuvel J, Bisgaard S, Does RJ. Lean six sigma in healthcare. J Healthc Qual. 2006;28(2):4-11.

37. Niemeijer GC, Flikweert E, Trip A, et al. The usefulness of lean six sigma to the development of a clinical pathway for hip fractures. $J$ Eval Clin Pract. 2013;19(5):909-914.

38. Nicolay CR, Purkayastha S, Greenhalgh A, et al. Systematic review of the application of quality improvement methodologies from the manufacturing industry to surgical healthcare. Br J Surg. 2012;99(3): 324-335.

39. Fleurence R, Selby JV, Odom-Walker K, et al. How the Patient-Centered Outcomes Research Institute is engaging patients and others in shaping its research agenda. Health Aff (Millwood). 2013;32(2):393-400.

40. Bate P, Robert G. Experience-based design: from redesigning the system around the patient to co-designing services with the patient. Qual Saf Health Care. 2006;15(5):307-310.

41. Millenson ML, DiGioia AM 3rd, Greenhouse PK, Swieskowski D. Turning patient-centeredness from ideal to real: lessons from 2 success stories. J Ambul Care Manage. 2013;36(4):319-334.

42. DiGioia AM3rd, Greenhouse PK. Care experience-based methodologies: performance improvement roadmap to value-driven health care. Clin Orthop Relat Res. 2012;470(4):1038-1045.

43. Joint Commission Resources. Looking at sentinel events along the continuum of patient safety: a future direction for the Sentinel Event Policy. JCAH Perspect. 2010;30(8):3-5. 
44. Auspitz M, Cleghorn MC, Tse A, et al. Understanding quality issues in your surgical department: comparing the ACS NSQIP with traditional morbidity and mortality conferences in a Canadian academic hospital. $J$ Surg Educ. Epub 2015 Jun 25.

45. Percarpio KB, Watts BV, Weeks WB. The effectiveness of root cause analysis: what does the literature tell us? Jt Comm J Qual Patient Saf. 2008;34(7):391-398.

46. Bagian JP, Bonacum D, DeRosier J, et al. $R C A^{2}$ : Improving Root Cause Analyses and Actions to Prevent Harm. Boston: National Patient Safety Foundation (NPSF); 2015. Available from: http://www.npsf.org/ resource/resmgr/PDF/RCA2_first-online-pub_061615.pdf. Accessed September 26, 2015.
47. McGinn T, Conte JG, Jarrett MP, ElSayegh D. Decreasing mortality for patients undergoing hip fracture repair surgery. Jt Comm J Qual Patient Saf. 2005;31(6):304-307.

48. Williams E, Talley R. The use of failure mode effect and criticality analysis in a medication error subcommittee. Hosp Pharm. 1994;29:331-332, 334-336, 339.

49. Adachi W, Lodolce AE. Use of failure mode and effects analysis in improving safety of iv drug administration. Am J Health Syst Pharm. 2005;62:917-920

\section{Publish your work in this journal}

Orthopedic Research and Reviews is an international, peer-reviewed, open access journal focusing on the patho-physiology of the musculoskeletal system, trauma, surgery and other corrective interventions to restore mobility and function. Advances in new technologies, materials, techniques and pharmacological agents are particularly welcome. The journal welcomes

\section{Dovepress}

original research, clinical studies, reviews \& evaluations, expert opinion and commentary, case reports and extended reports. The manuscript management system is completely online and includes a very quick and fair peer-review system, which is all easy to use. Visit http://www.dovepress. com/testimonials.php to read real quotes from published authors.

Submit your manuscript here: http://www.dovepress.com/orthopedic-research-and-reviews-journal 